\title{
Angiography Based Evaluation on the Relationship Between Serum Uric Acid Levels and Severity of Coronary Artery Disease in the Patients of StableAngina
}

\section{Seyed Mohammad Reza Afshani, Mahla Sadat Masoomi*}

Department of Cardiovascular Diseases, Ahvaz Jundishapur University of Medical Sciences, Ahvaz, Iran

Study Area: Ahvaz, Iran

Coordinates: $31^{\circ} 19^{\prime} 13^{\prime \prime} \mathrm{N} ; 48^{\circ} 40^{\prime} 09^{\prime \prime E}$

Keywords: Hyperuricemia, Angiography

Ethical declaration: All experimental procedures of this study were approved by local ethics committee of All experimental procedures were approved by local ethics committee of AJUMS, Ahvaz, Iran (ethics code:IR.AJUMS.REC.1397.213) which were in complete accordance with the ethical standards and regulations of human studies set by the Helsinki declaration (2014).

\section{Introduction:}

Coronary heart disease (CAD) is characterized by reduced blood flow to the heart muscle due to the buildup of plaque in the arteries of the heart that causes to lose the smooth, elastic lining inside the coronary artery. The artery's lining becomes hardened and stiffened which leads to developing atherosclerosis (Mendis \& Puska, 2011). CAD is one of the most common cardiovascular diseases and the leading cause of death in the world. As per a report CAD is the main cause of about 6oo, ooo deaths in the United States each year (Kochanek et al., 2009).

Serum uric acid (SUA) is the final product of purine nucleotide metabolism which is degraded to adenosine and guanine (Feig et al., 2008). Through various mechanisms, uric acid reduces nitric oxide in endothelial cells. Nitric oxide plays an important role in regulating the tone and structure of vessels. Consequently, a high concentration of

\section{Abstract}

Multiple risk factors are there to develop coronary artery disease (CAD) one of which is a high level of uric acid. Various studies have evaluated the effect of serum uric acid on coronary artery disease, overall results, however, remain controversial. We aimed to investigate the association between serum levels of uric acid and the severity of coronary artery disease in patients with stable angina. The analytical epidemiological study was conducted on 274 patients with stable coronary artery disease based on angiographic indications. The data on the presence and severity of coronary atherosclerosis were collected using a customized questionnaire and Gensini score (GS) and organized into statistical package SPSS for further analyses. The GS score increased with age, hyperlipidemia, diabetes, and glomerular filtration rate (GFR<9o). GS in men with hyperuricemia was statistically higher than the women and was more than those without hyperuricemia. Hyperuricemia was higher in males than in females and it revealed an inverse relation with age in the males. After three months, the serum levels of uric acid in the losartan treated patients significantly reduced, whereas the betablocker treated patients showed increased serum levels. Our findings showed increased serum levels of uric acid developed the severity of coronary artery disease and this relationship was significant only in men.

uric acid results in decreasing levels of intracellular nitric oxide and dysfunction of endothelial cells (Papežíková et al., 2013; Xuan et al., 2012, 2015). Also, uric acid causes to replicate vascular smooth muscle cell (VSMC), produce angiotensin II, and oxidative stress via renin-angiotensin system (RAS). This suggests that uric acid stimulates RAS causing cardiovascular disorders which can be triggered by mitogen-activated protein pathway (MAP)(Corry et al., 2008). Although earlier reports indicated that high levels of uric acid are accompanied by the risk of coronary artery disease, there is still controversy regarding the connection of uric acid to other risk factors of the physiological system. On the other hand, most of the studies indicated the role of uric acid as an inflammatory factor in coronary artery disease in acute coronary syndrome, but its role in patients with chronic angina is not very clear (Alderman \& Aiyer, 2004; Baker et al., 2005; Goodarzynejad et al., 2010; Jelic- 
Ivanovic et al., 2007). This study is to evaluate the association between hyperuricemia and severity of CAD considering other traditional risk factors through GS in patients with stable angina for preventing and treating this disease.

\section{Methodology:}

Study design and participants: this analytical epidemiology study was performed on 274 patients with stable ischemic heart disease based on angiographic indications who referred to the angiography departments of Golestan and Imam Khomeini Hospitals, Ahvaz, Iran during 2017. The researchers of the study clearly explained the aims, objectives, benef its and potential adverse effects of participating to the study to all subjects after the enrolment and prior to initiate the experimental procedures and all patients signed a written consent form for participation in the study. The experimental procedures including interventions, interviews, and data collections were performed in the angiography departments of Golestan Hospital and Imam Khomeini Hospital, Ahvaz, Iran, the year 2017. The inclusion criterion was age greater than 18 years old with confirming ischemic heart disease. The exclusion criteria were incomplete medical records, history of heart failure and inflammatory diseases such as collagen and vascular diseases, acute and chronic infectious diseases, history of previous coronary stenting and coronary artery bypass graft (CABG), normal coronary angiography, alcohol consumption, use of vitamin supplements including vitamin $\mathrm{C}$, niacin, and folate, history of autoimmune,neoplastic and chronic liver disease, severe renal dysfunction $(\mathrm{GFR}<30)$, acute myocardial infarction, and acute coronary syndrome.

A custom-designed questionnaire was used to collect clinical and demographic data of the patients. The data included age, sex, family history of heart disease (in firstdegree relatives, women $<65$ and men <55years of age), hypertension (systolic blood pressure $=140 \mathrm{~mm} \mathrm{Hg}$ and/or diastolic blood pressure $=90 \mathrm{~mm} \mathrm{Hg}$ ), dyslipidemia (increase in triglyceride, LDL cholesterol, and decrease in HDL), diabetes mellitus (fasting blood glucose $=126$ $\mathrm{mg} / \mathrm{dl}$ ), GFR, taking drugs (losartan, beta-blocker), and smoking habits and were collected by one researcher through interview with patients and from their medical records. Then, the presence and severity of atherosclerosis were determined using the GS inventory. The scores were calculated based on the type of vessel, involved site, and the percentage of coronary artery stenosis. Uric acid was measured by the enzymatic method in which uricase enzyme decomposes uric acid into allantoin and oxygenated water. The optical absorption of water soluble compound decreases at a wavelength of $290 \mathrm{~nm}$. The reduction of optical absorption depends on the amount of uric acid in the sample.
Statistical analysis: the data were analyzed with the statistical package (IBM SPSS Statistics Version 22). For the quantitative variables, the mean and median were used to describe the data center and standard deviation and interquartile range was applied to describe the data dispersion. Frequency and percentage were employed to describe the data in qualitative variables. The main tests for the assessment of normality were Kolmogorov-Smirnov (KS) and Q-Q diagrams. The square root transformation was applied to normalize GS variable. Independent t-test, analysis of variance (ANOVA), and Pearson correlation tests were used for univariate analysis. Backward elimination approach for multiple linear regression was employed for multi-variableanalysis. The 0.05 was set as the statistical signif icance for all analyses.

\section{Results:}

Out of the 274 patients, $176(64.2 \%)$ were male and 98 $(35.8 \%)$ female. The mean age was $59.45 \pm 11.95$. The demographic information along with the clinical parameters of the study are presented in the Table-1.

Table-1: Characteristics of the study population. Data are presented as mean $\pm \mathrm{SD}$

\begin{tabular}{|c|c|c|c|c|}
\hline Variables & & $\mathrm{N}(\%)$ & Variables & $\mathrm{N}(\%)$ \\
\hline Sex & $\begin{array}{l}\text { Male } \\
\text { Female }\end{array}$ & $\begin{array}{l}176(64.2) \\
98(35.8)\end{array}$ & $\begin{array}{l}\text { GFR } \geq 90 \\
\text { GFR }<90\end{array}$ & $\begin{array}{l}198(72.3) \\
76(27.7)\end{array}$ \\
\hline$(\mathrm{Mean} \pm \mathrm{SD})$ & & & $\begin{array}{l}\mathrm{TC}^{*}(\mathrm{mg} / \mathrm{dl})-\text { Normal } \\
\mathrm{TC}^{*}(\mathrm{mg} / \mathrm{dl})-\text { High }\end{array}$ & $\begin{array}{l}170(62) \\
104(38)\end{array}$ \\
\hline & $\begin{array}{l}\text { No } \\
\text { Yes }\end{array}$ & & $\begin{array}{l}\text { Hyperlipidemia-No } \\
\text { Hyperlipidemia- Yes }\end{array}$ & $\begin{array}{l}123(44.9) \\
151(55.1)\end{array}$ \\
\hline $\begin{array}{l}\text { Blood- } \\
\text { Pressure }\end{array}$ & $\begin{array}{l}\text { Normal } \\
\text { High }\end{array}$ & & & $\begin{array}{l}197(71.9) \\
77(28.1)\end{array}$ \\
\hline $\begin{array}{l}\text { Dyslipi- } \\
\text { demia }\end{array}$ & $\begin{array}{l}\text { No } \\
\text { Yes }\end{array}$ & $\begin{array}{l}29(10.6) \\
245(89.4)\end{array}$ & & $\begin{array}{l}210(76.6) \\
64(23.4)\end{array}$ \\
\hline $\begin{array}{l}\text { HDL, } \\
(\mathrm{mg} / \mathrm{dl})\end{array}$ & $\begin{array}{l}\text { Normal } \\
\text { Low }\end{array}$ & $\begin{array}{l}62(22.6) \\
212(77.4)\end{array}$ & & $\begin{array}{l}180(65 \cdot 7) \\
94(34 \cdot 3)\end{array}$ \\
\hline $\begin{array}{l}\text { LDL, } \\
(\mathrm{mg} / \mathrm{dl})\end{array}$ & $\begin{array}{l}\text { Normal } \\
\text { High }\end{array}$ & $\begin{array}{l}168(61.3) \\
106(38.7)\end{array}$ & $\begin{array}{l}\text { ß-blockers- No } \\
\text { ß-blockers- Yes }\end{array}$ & $\begin{array}{l}98(35.8) \\
176(64.2)\end{array}$ \\
\hline Trigly- & Normal & $202(73.7)$ & $\begin{array}{l}\text { Triglycerides- High } \\
(\mathrm{mg} / \mathrm{dl})\end{array}$ & $72(26.3)$ \\
\hline
\end{tabular}

\section{*Total Cholesterol}

The correlation coefficients of age and uric acid with GS score are respectivelyo.115 $(\mathrm{P}=0.012)$ and $0.286(\mathrm{P}<0.001)$, which are statistically significant. It indicates, GS increases with age and serum uric acid. The GS score has a statistically signif icant relationship with gender, diabetes mellitus, hypertension, LDL, GFR $<90$, triglycerides, cholesterol, hyperlipidemia, and hyperuricemia. The associations between other biochemical parameters and GS are shown in Table-2.

In the backward elimination approach, the variables that were associated with GS remained. Through controlling other variables, GS increased with age, diabetes 
mellitus, GFR <9o, and hyperlipidemia. These relationships were statistically significant (Table-3). GS in men with or without hyperuricemia was more as compared to respective women ( $<<0.001)$. The GS in the men with hyperuricemia was more than those without hyperuricemia $(\mathrm{p}<\mathrm{o.0o1})$. GS in women with hyperuricemia was more than those without hyperuricemia but the difference was not supported statistically $(\mathrm{p}<0.856)$.

Table-2: Relationship between GS and other variables in univariate analysis

\begin{tabular}{|c|c|c|c|c|}
\hline \multicolumn{2}{|l|}{ Variables } & $\mathrm{N}(\%)$ & Mean \pm SD & $\mathrm{P}$ \\
\hline Sex & $\begin{array}{l}\text { Male } \\
\text { Female }\end{array}$ & $\begin{array}{l}39(52) \\
32.5(30)\end{array}$ & $\begin{array}{l}52.99 \pm 38.39 \\
37.19 \pm 23.58\end{array}$ & $<0.001$ \\
\hline $\operatorname{Age}(\mathbf{r})$ & & & 0.151 & $<0.012$ \\
\hline $\begin{array}{l}\text { Diabetes } \\
\text { mellitus }\end{array}$ & $\begin{array}{l}\text { No } \\
\text { YES }\end{array}$ & $\begin{array}{l}34(38) \\
32(72)\end{array}$ & $\begin{array}{l}39.96 \pm 24.06 \\
58.69 \pm 44.20\end{array}$ & $<0.001$ \\
\hline $\begin{array}{l}\text { Blood } \\
\text { pressure }\end{array}$ & $\begin{array}{l}\text { Normal } \\
\text { High }\end{array}$ & $\begin{array}{l}34(45) \\
37(37)\end{array}$ & $\begin{array}{l}42.08 \pm 29.01 \\
53.18 \pm 39.26\end{array}$ & $<0.01$ \\
\hline Dyslipidemia & $\begin{array}{l}\text { No } \\
\text { Yes }\end{array}$ & $\begin{array}{l}32(43) \\
34(40)\end{array}$ & $\begin{array}{l}48.31 \pm 35.95 \\
47.23 \pm 34.55\end{array}$ & $>0.848$ \\
\hline HDL, mg/dl & $\begin{array}{l}\text { Normal } \\
\text { low }\end{array}$ & $\begin{array}{l}32(24) \\
35 \cdot 5(44)\end{array}$ & $\begin{array}{l}48.47 \pm 39.48 \\
47.01 \pm 33.18\end{array}$ & $>0.789$ \\
\hline LDL, mg/dl & $\begin{array}{l}\text { Normal } \\
\text { High }\end{array}$ & $\begin{array}{l}30.5(28) \\
49(70)\end{array}$ & $\begin{array}{l}36.52 \pm 22.30 \\
64.50 \pm 42.94\end{array}$ & $<0.001$ \\
\hline $\begin{array}{l}\text { Triglycerides, } \\
\text { mg/dl }\end{array}$ & $\begin{array}{l}\text { Normal } \\
\text { High }\end{array}$ & $\begin{array}{l}32(38) \\
46(70)\end{array}$ & $\begin{array}{l}42.02 \pm 29.92 \\
62.26 \pm 42.10\end{array}$ & $<0.001$ \\
\hline $\begin{array}{l}\text { GFR } \\
\text { GFR }\end{array}$ & $\begin{array}{l}=90 \\
<90\end{array}$ & $\begin{array}{l}30(41) \\
48(45)\end{array}$ & $\begin{array}{l}43.92 \pm 35.29 \\
56.26 \pm 31.36\end{array}$ & $<0.001$ \\
\hline $\begin{array}{l}\text { Total cholesterol } \\
\mathrm{mg} / \mathrm{dl}\end{array}$ & $\begin{array}{l}\text { Normal } \\
\text { High }\end{array}$ & $\begin{array}{l}32(38) \\
43(56)\end{array}$ & $\begin{array}{l}40.74 \pm 27.17 \\
58.13 \pm 42.18\end{array}$ & $<0.001$ \\
\hline Hyperlipidemia & $\begin{array}{l}\text { No } \\
\text { Yes }\end{array}$ & $\begin{array}{l}34(36) \\
42(54)\end{array}$ & $\begin{array}{l}39.31 \pm 22.51 \\
53.89 \pm 40.93\end{array}$ & $<0.003$ \\
\hline Smoking & $\begin{array}{l}\text { No } \\
\text { YES } \\
0.6\end{array}$ & $\begin{array}{l}38(37) \\
30(55)\end{array}$ & $\begin{array}{l}47.63 \pm 33.04 \\
46.60 \pm 38.65\end{array}$ & $>0.6$ \\
\hline Family history & $\begin{array}{l}\text { No } \\
\text { YES }\end{array}$ & $\begin{array}{l}34(45) \\
34(27)\end{array}$ & $\begin{array}{l}49.13 \pm 36.38 \\
41.48 \pm 27.61\end{array}$ & $<0.210$ \\
\hline Uric $\operatorname{acid}(\mathbf{r})$ & & & 0.286 & $<0.001$ \\
\hline Hyperuricemia & $\begin{array}{l}\text { No } \\
\text { YES }\end{array}$ & $\begin{array}{l}41.41(39) \\
50(77)\end{array}$ & $\begin{array}{l}44 \pm 31.42 \\
66.34 \pm 45.05\end{array}$ & $<0.001$ \\
\hline
\end{tabular}

Table-3: Relationship between GS and other variables in multivariable analysis

\begin{tabular}{llll}
\hline \hline Variable & $\mathrm{B}$ & $\mathrm{CI}$ & p value \\
\hline \hline Age & 0.052 & $(\mathrm{o} .029,0.076)$ & $<0.001$ \\
Diabetes mellitus (Yes to No) & 0.951 & $(0.440,1.462)$ & $<0.001$ \\
Hyperlipidemia (Yes to No) & 0.483 & $(-0.017,0.983)$ & $>0.058$ \\
GFR (GFR<9o to GFR=90) & 0.769 & $(0.167,1.372)$ & $<0.012$ \\
No hyperuricemia (O to O') & -1.151 & $(-1.719,-0.582)$ & $<0.001$ \\
Hyperuricemia(O to O') & -3.729 & $(-5.071,-2.387)$ & $<0.001$ \\
Hyperuricemia Ơ (Yes to No) & 2.471 & $(1.550,3.391)$ & $<0.001$ \\
Hyperuricemia O(Yes to No) & -0.107 & $(-1.267,1.052)$ & $>0.856$ \\
\hline
\end{tabular}

$\mathrm{B}=$ Unstandardized coefficient; $\mathrm{CI}=$ Conf idence internal

The relationship between age and hyperuricemia in men was negative and significant. It means that hyperuricemia is significantly reduced by increasing age in the men $(\mathrm{r}=-0.299 ; \mathrm{p}<0.001)$. But, there was no significant association between age and hyperuricemia in women $(\mathrm{r}=-$ o.027; $\mathrm{p}>0.793$ ).

Out of 274 patients with CAD, 25 patients took only losartan and 106 used just ß-blocker. After three months, the mean serum level of uric acid in the patients received losartan was reduced but increased in those patients received ß-blocker $(\mathrm{p}<0.001)$ (Table-4).

Table-4: Relationship of losartan and ß-blocker with hyperuricemia (Uric acid level)

\begin{tabular}{llll}
\hline Variable & At beginning of study & After 3 months & P value \\
\hline Losartan & $5.18+0.81$ & $5.04+0.83$ & $<0.001$ \\
B-blocker & $4.76+1.53$ & $4.89+1.54$ & $<0.001$ \\
\hline
\end{tabular}

\section{Discussion:}

This study was conducted to determine the relationship between serum level of uric acid and the severity of atherosclerosis in patients having stable cardiac ischemia. Results revealed a positive correlation between SUA level and CAD i.e., increase uric acid levels was accompanied by. This relationship was only identified in men. GS in men with or no hyperuricemia was more than women with or no hyperuricemia. Also, GS in the men with hyperuricemia were higher than in those without hyperuricemia. Barbieri et al. (2015) also reported that the incidence of coronary artery disease and complicated coronary lesions was higher in men. The study of Goodarzinejad et al. (2010) reported an independent association of hyperuricemia with the severity of coronary artery disease in men that was more than women . Finegold et al. (2013) found that men are more affected by coronary artery disease than women. These studies were consistent with our results.

GS increases with age in the subjects of this research. Our findings were strengthening the earlier reports i.e., the prevalence of coronary artery disease significantly increased with age in men and women. The CAD may affect people of different ages but in older people, it dramatically increases by about three times in each decade of life (Finegold et al., 2013).

In the present study, hyperuricemia in men was found to be inter-related with the decrease of age, but no significant association between age and hyperuricemia in women was evidenced. In a cross-sectional study (20142017), Sun et al. (2019) indicated that uric acid levels signif icantly change with age in men and women. The level of uric acid or hyperuricemia meaningfully increases with age in women, while in men a declined trend was found. The correlation between uric acid and CAD varied according to age and sex. There was a significant association between uric acid and hyperuricemia with CAD in women, especially in elderly women $=80$ years, but in men, this relationship was not significant (Sun et al., 2019). Tian et al. (2015) 
concluded that the highest level of hyperuricemia was in older women not in older men. The results of these studies are consistent with our findings in the downward trend of hyperuricemia in men with increasing age but inconsistent with the upward trend of hyperuricemia in women. The difference in the relationship between hyperuricemia and the severity of coronary artery disease in both sexes can be due to genetic differences that affect synthesis, secretion, and uptake of uric acid and, in turn, level of uric acid. Perhaps it is necessary to classify different age groups in men and women to obtain precise results.

Komendarek-Kowalska (2017) reported a positive correlation between serum creatinine and serum uric acid and a negative correlation between uric acid and eGFR. High levels of uric acid may result in hypertension and kidney damage due to hypertension. Also, a systematic and meta-analysis study (Li et al., 2014) determined that during long-term follow-up of non-CKD subjects, high levels of uric acid increase the risk of chronic kidney disease and GFR reduction. These findings suggest that uric acid is a progressive and predictive change in kidney function. Our study showed that GS increased with low GFR. It is possible that high uric acid reduces GFR and increases the incidence of coronary artery disease.

GS increased with hyperlipidemia in patients of the present study. Previous investigations have proven that serum uric acid has a positive and significant correlation with LDL, triglyceride, creatinine, and hyperlipidemia (Maiuolo et al., 2016), which supports our findings.

LDL and serum uric acid were predictors of coronary artery disease in diabetic patients. A positive correlation was found between serum levels of uric acid and the duration of diabetes, HDL, hypertension, and triglyceride (Jayashankar et al., 2016). In the current study, GS had a significant relationship with diabetes. Hyperuricemia can be an effective variable in the incidence of coronary artery disease in diabetic patients.

Matsumura et al. (2015) investigated the effect of losartan on serum levels of uric acid in patients with hypertension treated with thiazide diuretics for 6 months. Although the blood pressure level was not significantly differed in their study as the case with the control group (combination of an angiotensin II receptor blocker (ARB) except losartan and thiazide diuretics) and the combination pill (losartan and hydrochlorothiazide) group. The decrease in serum uric acid level in the combined pill group was significantly higher than that in the control group. These results indicated that losartan has a positive effect on the level of serum uric acid even in combination treatment with thiazide diuretics. Losartan may be useful in maintaining normal levels of uric acid in patients with high blood pressure, especially in patients with hyperuricemia, who were consuming diuretic thiazide (Matsumura et al., 2015). Ueno et al. (2015) reported that uric acid was significantly higher in the patients treated with diuretics, beta-blockers, or alpha-1 blockers than in those who were not treated with those drugs that cause to reduce GFR levels. Calcium channel blockers, ACE inhibitors, and angiotensin receptor blockers, including losartan, do not increase the level of uric acid (Ueno et al., 2015). Our study compared the patients consuming only losartan with those taking just beta-blocker. We found that the level of uric acid in patients using losartan was reduced but increased in those taking beta-blocker which agrees with the previous findings. Considering the effect of losartan on the reduction of uric acid levels, it can be used as an effective drug for controlling hypertension in people with hyperuricemia, especially in young men who are more at risk for hyperuricemia.

Thus, it is recommended to carry out clinical trial studies that determine whether reduce in uric acid levels causesto prevent or decrease the severity of coronary artery disease or not.

\section{Conclusion:}

The GS score increased with age, hyperlipidemia, diabetes, and GFR<9o. The GS in the males with or no hyperuricemia was higher than their counterpart females. GS in men with hyperuricemia was also more than those without hyperuricemia. Therefore, the rate of coronary artery involvement increases with uric acid level and this relationship is signif icant only in men. The results indicated that levels of uric acid in the patients treated with losartan reduced but increased in those treated with beta-blockers.

\section{Acknowledgements:}

This study was financially supported by the Cardiovascular Research Center, Ahvaz Jundishapur University of Medical Sciences, Ahvaz, Iran (Grant no. CVRC-9708).

\section{References:}

Alderman, M. \& Aiyer, K.J. (2004): Uric acid: role in cardiovascular disease and effects of losartan. Curr. Med. Res. Opin., 20(3):369-379.

Baker, J.F., Krishnan, E., Chen, L. \& Schumacher, H.R. (2005): Serum uric acid and cardiovascular disease: recent developments, and where do they leave us? Am. J. Med. $118(8): 816-826$

Barbieri, L., Verdoia, M., Schaffer, A., Marino, P., Suryapranata, H., De Luca, G. \& Novara Atherosclerosis Study Group (NAS) (2015): Impact of sex on uric acid levels and its relationship with the extent of coronary artery disease: A single-centre study. Atherosclerosis, 241(1):241-248.

Corry, D.B., Eslami, P., Yamamoto, K., Nyby, M.D., Makino, H. \& Tuck, M.L. (2008): Uric acid stimulates vascular smooth muscle cell proliferation and oxidative stress via the vascular renin-angiotensin system. L. Hypertens., 26(2):269-275.

Feig, D.I., Kang, D.H. \& Johnson, R.J. (2008): Uric acid and cardiovascular risk. N. Engl.J.Med., 359(17):1811-1821.

Finegold, J.A., Asaria, P. \& Francis, D.P. (2013): Mortality from ischaemic heart disease by country, region, and age: statistics 
from World Health Organisation and United Nations. Int. J. Cardiol., 168(2):934-945.

Goodarzynejad, H., Anvari, M.S., Boroumand, M.A., Karimi, A., Abbasi, S.H. \& Davoodi, G.(2010): Hyperuricemia and the

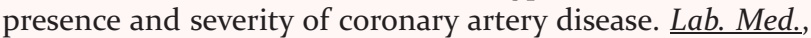
41(1):40-45.

Jayashankar, C.A., Andrews, H.P., Vijayasarathi, V.B.P., Shashidharan, B., Kumar, H.N. \& Vemulapalli, S. (2016): Serum uric acid and low-density lipoprotein cholesterol levels are independent predictors of coronary artery disease in Asian Indian patients with type 2 diabetes mellitus. L. Nat. Sci., Biol.Med., 7(2):161-165.

Jelic-Ivanovic, Z., Memon, L., Spasojevic-Kalimanovska, V., Bogavac-Stanojevic, N. \& Spasic, S. (2007): Independent association of high serum uric acid concentration with angiographically def ined coronary artery disease. Tohoku J. Exp. Med., 211(4):369-377.

Kochanek, K.D., Minin o, A.M., Murphy, S.L., Xu, J. \& Kung, H.C. (2011): Deaths: final data for 2009. Nat. Vital Stat. Rep., 6o(3):1-116.

Komendarek-Kowalska, M. (2017): The assessment of renal function in patients with newly diagnosed hypertension-the role of hyperuricemia as a risk factor for chronic kidney disease-preliminary study. Pol. Merkur. Lekarski, 42(251):193196.

Li, L., Yang, C., Zhao, Y., Zeng, X., Liu, F. \& Fu, P. (2014): Is hyperuricemia an independent risk factor for new-onset chronic kidney disease?: A systematic review and metaanalysis based on observational cohort studies. $\underline{B M C}$ Nephrol.,15(1):122.

Maiuolo, J., Oppedisano, F., Gratteri, S., Muscoli, C. \& Mollace, V. (2016): Regulation of uric acid metabolism and excretion. Int. J. Cardiol., 213:8-14.

Matsumura, K., Arima, H., Tominaga, M., Ohtsubo, T., Sasaguri, T., Fujii, K., , Fukuhara, M., Uezono, K., Morinaga, Y., Ohta, Y., Otonari, T., Kawasaki, J., Kato, I., Tsuchihashi T. \& COMFORT Investigators (2015): Effect of losartan on serum uric acid in hypertension treated with a diuretic: the COMFORT study. Clin. Exp. Hypertens., 37(3):192-196.
Mendis, S., Puska, P., Norrving, B. \& Organization, W.H. (2011): Global atlas on cardiovascular disease prevention and control. Pub. by: World Health Organization in collaboration with the World Heart Federation and the World Stroke Organization. P. 166.

Papežíková, I., Pekarová, M., Kolárová, H., Klinke, A., Lau, D., Baldus, S., Lojek, A. \& Kubala, L. (2013): Uric acid modulates vascular endothelial function through the down regulation of nitric oxide production. Free Radic. Res., 47(2):82-88.

Sun, Y., Zhang, H., Tian, W., Shi, L., Chen, L., Li, J., Zhao, S. \& Qi, G. (2019): Association between serum uric acid levels and coronary artery disease in different age and gender: a crosssectional study. Aging Clin. Exp. Res., doi: 10.1007/s40520019-01137-2.

Tian, Y., Chen, K., Xie, Z., Fang, Y., Wang, H., Nie, Y., Hu, D. \& Mu, Y. (2015): The association between serum uric acid levels, metabolic syndrome and cardiovascular disease in middle aged and elderly Chinese: results from the DYSlipidemia International Study. BMC Cardiovasc. Disord., 15(1):66.

Ueno, S., Hamada, T., Taniguchi, S., Ohtani, N., Miyazaki, S., Mizuta, E., Ohtara, A., Ogino, K., Yoshida, K., Ninomiya, H., Kotake, H., Taufiq, F., Yamamoto, K. \& Hisatome, I. (2016): Effect of antihypertensive drugs on uric acid metabolism in patients with hypertension: cross-sectional cohort study. DrugRes. (Stuttg), 66(12):628-632.

Xuan, C., Chang, F.J., Liu, X.C., Bai, X.Y., Liao, X.L., He, G.W. \& Ou, J.S. (2012): Endothelial nitric oxide synthase enhancer for protection of endothelial function from asymmetric dimethylarginine-induced injury in human internal thoracic artery. J. Thorac. Cardiovasc. Surg., 144(3):697-703.

Xuan, C., Lun, L.M., Zhao, J.X, Wang, H.W, Wang, J., Ning C.P, Liu, Z., Zhang, B.B., He, G.W. (2015): L-citrulline for protection of endothelial function from ADMA-induced injury in porcine coronaryartery. Sci. Rep., 5:10987. 